\title{
STUDI KARAKTERISTIK MOMEN TORSI AKUMULATOR PEGAS UNTUK PENGGERAK LANGKAH (STEP-DRIVES)
}

\author{
Danny S. Pelupessy \\ e-mail: otobox@yahoo.com \\ Program Studi Teknik Sistem Perkapalan, Fakultas Teknik Unpatti - Ambon
}

\begin{abstract}
ABSTRAK
This paper considers and analyzes the torque characteristics of spring accumulators with output rotary link, designed for stepper drives, reciprocating movements and in balancing systems, provides recommendations for their use. General idea of realization of the principle of recuperation with accumulation of potential energy of the deformed springs in this work consists in use of spring accumulators with cylindrical springs of tension or compression.
\end{abstract}

Keyword: spring accumulator, step-drives, the moment characteristic, the recuperation energy, high-speed, nonreversing movement, reversing movement

\section{PENDAHULUAN}

Akumulator pegas (AP) muncul di sejumlah karya yang besar [1,2,4,15-17], tetapi dalam literatur teknis hampir tidak ada informasi tentang karakteristik AP dan metode perhitungannya, sehingga kontribusinya di berbagai aplikasi konstruksi hampir tidak kelihatan. AP dengan lengan (output rotary link) dapat digunakan sebagai penggerak dengan energi rekuperasi untuk pergerakan langkah dan menyeimbangkan perangkat [7-9]. Penerapan lain dari AP bisa sebagai penggerak dengan bolak balik (reciprocating movement) $[5,13,14,17]$. Penelitian ini menganalisis karakteristik torsi dari AP dengan lengan berputar yang bertujuan memberikan rekomendasi untuk penggunaan mereka di berbagai bidang. Sebagai penggerak utama untuk rotary table drive, seperti ditampilkan dalam gambar 1, dapat digunakan AP dengan lengan berputar berdasarkan pegas tarik seperti pada gambar 2 atau pegas tekan, serta dapat pula menggunakan kombinasi pegas dan elemen fleksibel yang terpasang antara lengan berputar dan pegas (gambar 3). AP seperti ini dapat diimplementasikan sebagai penggerak langkah (stepper drive) untuk gerakan non-reversible dan reversible [14]. Seperti saat operasi pengerjaan berlangsung, konsumsi daya mencapai puncak, hal ini disebabkan oleh kebutuhan untuk mempercepat dan mengurangi momen inersia dari link, kerja peralatan dan tools, dan dengan peningkatan produktivitas ada peningkatan tajam dalam biaya energi. Penggunaan robot di industri, mengatasi masalah konsumsi energi, prinsipnya dengan bantuan penggerak rekuperasi baik siklik maupun gerak bolak balik (reciprocating). Namun, sistem robot selalu memerlukan penggunaan berbagai peralatan teknologi operasi dalam mode langkah (step-movement), misalnya, transportasi dan sistem penyimpanan, meja putar (rotary table), dan lainlain.

Mekanisme siklik, diterapkan dalam banyak proses manufaktur, yang meliputi:

- instalasi transportasi benda kerja dari dan ke posisi pengerjaan

- pergerakan tools

- memindahkan komponen sesuai mode kerja.

Sebagai penggerak utama untuk meja putar (rotary table), seperti yang ditampilkan pada gambar 1, dapat digunakan AP dengan lengan berputar yang mengunakan pegas (baik pegas kompresi maupun pegas tarik), dan AP dengan elemen fleksibel yang terpasang antara lengan berputar dan katrol (gambar 3), dimana hal ini mendemontrasikan solusi variasi tata letak.

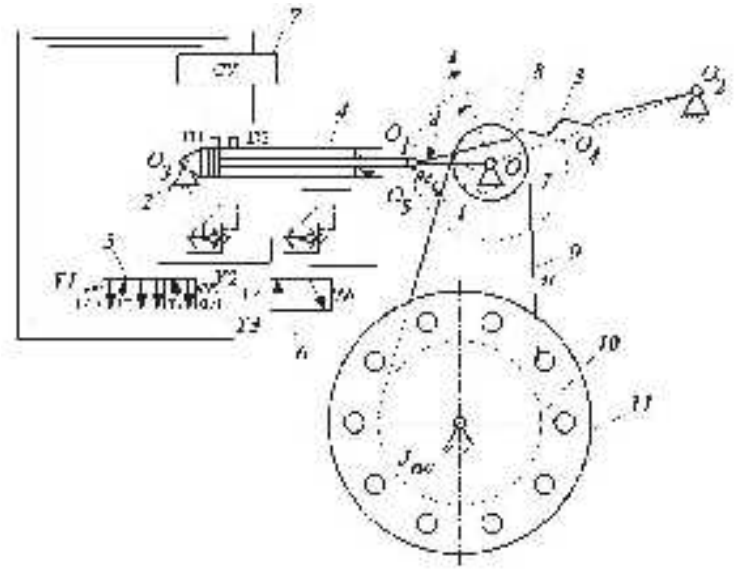

Gambar 1. Skema kinematik aktuator pegas nonreversing untuk penggerak langkah.

1 - lengan berputar; 2 - tumpuan; 3 - pegas; 4 selinder pneumatik; 5 -distributor; 6 -distributor untuk fiksator; 7 - sistim kontrol; 8 - puli penggerak; 9 - sabuk berprofil gigi; 10 - puli yang digerakkan; 11 - meja putar 


\section{KAJIAN TEORI DAN METODE}

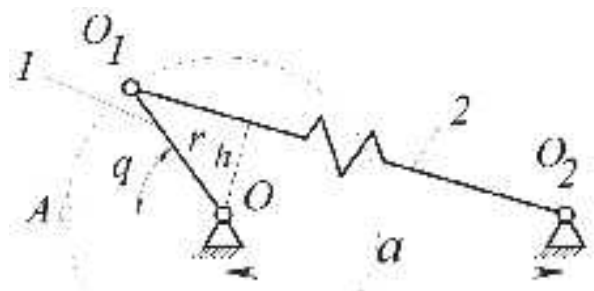

Gambar 2. Diagram AP dengan lengan berputar dan pegas tarik: 1-lengan berputar, 2-pegas

Akumulator pegas seperti pada gambar 2 dikenal di berbagai literatur sebagai crank-rocker mechanism. Akumulator pegas ini memiliki sudut putar $2 \pi$, dapat digunakan sebagai penggerak meja putar (rotary table) peralatan teknik. Pada gambar terlihat sebuah AP dengan lengan berputar 1 yang terhubung dengan pegas tarik silindris 2, ujungnya terpasang engsel tetap. Ketika AP berputar mengelilingi sumbu, titik $O_{1}$ akan berputar sebesar sudut $q$. Karakteristik utama dari AP dengan lengan berputar ini dapat dilihat pada hasil perhitungan:

- Perubahan energi potensial, yang tergantung sudut putar;

- Gaya pegas;

- Konstanta pegas dan gaya maksimum;

- Perubahan momen putar;

- Kecepatan putar lengan;

- Waktu putar;

- Kehilangan disipasi.

Karena batasan dinamika dan struktural, tidak mungkin membuat AP dengan karakteristik torsi sinus dan sudut rotasi $2 \pi$. Tetapi AP dengan karakteristik torsi sinus dapat juga digunakan dalam sistem keseimbangan link di posisi vertikal dan sudut rotasi $\mathrm{q}<\pi$. Gambar 3 menunjukkan AP dengan elemen fleksibel dan dua pegas tarik. Pada titik $\mathrm{O}_{1}$, katrol tambahan 5 dipasang pada lengan berputar. Dua katrol 3 terpasang pada sumbu $\mathrm{O}_{2}$. AP dilengkapi dengan dua buah pegas 2 . terhubung satu sama lain dengan elemen fleksibel 4 , disisipi melalui katrol 3 dan 5 .

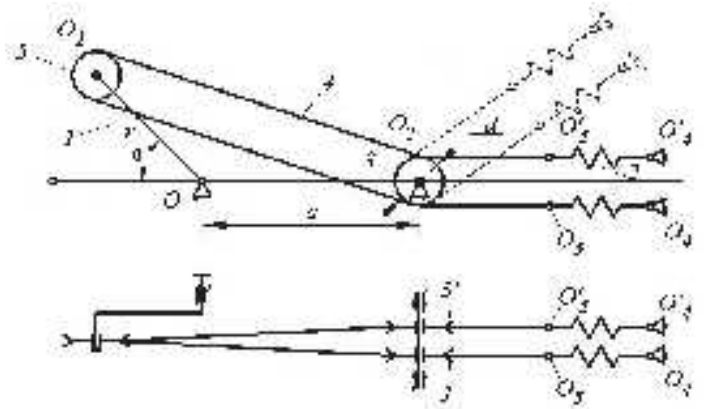

Gambar 3. Skema AP dengan elemen fleksibel dan dua pegas, menunjukkan solusi tata letak
Penggunaan AP dengan elemen fleksibel memberikan solusi tata letak. Perhitungan untuk AP ini menggunakan konstanta total dari pegas.

$c=c_{1}+c_{2}$ atau jika $c_{1}=c_{2}$, maka $c=2 c_{1}$. Karakteristik utama yang dipertimbangkan dari AP dengan lengan berputar adalah karakteristik torsi, yang menentukan gerak, ditentukan oleh persamaan berikut:

$$
M=a \cdot c \cdot r\left(1-\frac{a-r}{\sqrt{r^{2}+a^{2}+2 a c q}}\right) \cdot \sin q
$$

dimana $c$-konstanta pegas

$r$ - radius of the rotating arm

$a-$ jarak antara sumbu

$q$ - sudut rotasi lengan berputar

Jarak antar sumbu ditentukan oleh pegas yang dipilih, yang ini ditandai dengan gaya maksimum, kontanta pegas c dan koefisien perpanjangan $K_{\mathrm{y}}$. Untuk memudahkan penelitian dan analisis skema, diambil ukuran $r$ untuk unit satuan dan koefisien $a_{r}=\frac{a}{r}$ yaitu koefisien yang menunjukan daerah perubahan jarak antar sumbu: sebagai:

Kemudian persamaan (1) dapat ditulis

$$
\begin{aligned}
& M=c r^{2} M_{a} \\
& \operatorname{dimana} M_{a}=u_{\mathrm{r}}\left(1-\frac{a_{\mathrm{r}}-1}{\sqrt{1+a^{r^{\prime 2}}+2 a^{\prime} c} q}\right) \sin \varphi
\end{aligned}
$$

sebuah hubungan, yang menunjukkan karakteristik momen torsi dalam bentuk umum

\section{HASIL DAN PEMBAHASAN}

Gambar 4 menunjukkan grafik karakteristik momen torsi AP dengan lengan berputar untuk 5 variasi jarak antar sumbu.

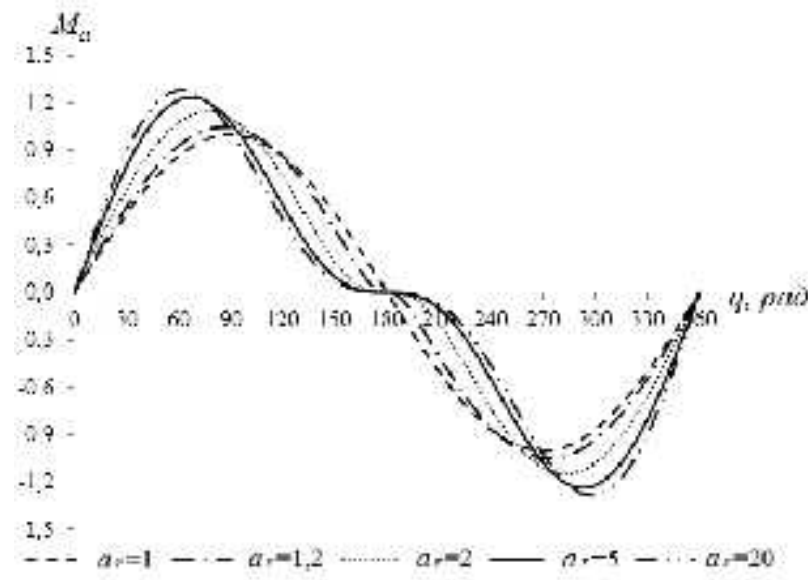

Gambar 4. Grafik karakteristik momen torsi $M_{a}$ terhadap sudut $q$ untuk $1 \leq a_{r} \leq 20$

Untuk mengidentifikasi karakteristik torsi yang mendekati pola sinusoidal, karakteristik torsi yang paling mendekati adalah berada pada $1 \leq a_{r} \leq 2$. 
Perlu dicatat bahwa jika mengubah parameter geometri, khususnya jarak antar sumbu, nilai maksimal saat itu meningkat dan bergeser ke posisi equilibrium tidak stabil. Analisis grafik menunjukan bahwa nilai maksimum dari torsi berbeda dengan karakteristik sinus tidak lebih dari $10 \%$ pada $1<a^{r} \leq 1,4$.

Dalam desain meja putar peralatan pengepakan tanpa pembatasan kecepatan, untuk meningkatkan kinerja kita dapat menggunakan nilai parameter desain $a_{r}=\frac{a}{r}>3$.

Dalam hal pembatasan akselerasi AP dengan lengan berputar, dipilih AP yang memiliki karakteristik yang mirip dengan akumulator berkarakter sinusoidal. Akumulator pegas dengan lengan berputar, yang dibuat dari elemen fleksibel memungkinkan untuk mendapatkan perkiraan terbaik dari karakteristik torsi sinusoidal dan juga menggunakan solusi tata letak yang berbeda.

Berikut ini dapat dilihat hukum gerak yang diperoleh dengan bantuan AP dengan lengan berputar. Gambar 5 menunjukkan karakteristik torsi dari akumulator pegas sinusoidal dan akumulator pegas untuk $a_{r}=5$.

Penggunaan AP dengan karakteristik torsi pada segmen $O_{1} O_{2}$ di aktuator pegas untuk gerak bolak balik (reciprocating movements) menunjukan ada upaya fiksasi pada titik ekstrim dengan pemberhentian, pada saat itu $q>2 \pi$. Pada segmen $\mathrm{OO}_{5}$ dimana akumulator pegas memiliki sudut rotasi $2 \pi$, karakteristik torsi terletak antara titik-titik equilium tidak stabil dan untuk itu diperlukan fiksator.

Pada bagian $\pi / 2 \leq q \leq \pi$ didapat karakteristik momen kosinus selanjutnya dapat dipakai untuk gerakan bolak balik dengan menggunakan fiksator untuk memastikan kestabilan saat memulai start kembali.

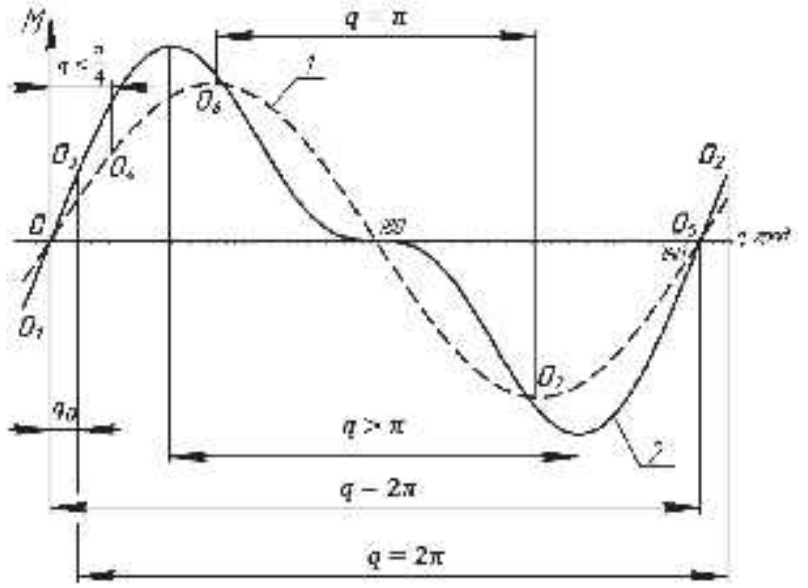

Gambar 5. Grafik karakteristik momen torsi AP, $1-a_{\mathrm{r}}=1,2-a_{\mathrm{r}}=5$

Segmen $\mathrm{O}_{4} \mathrm{O}$ praktis memiliki karakter linear, dan merupakan bagian dimana karakteristik torsi dapat digunakan untuk mendapatkan "inverse" karakteristik, ketika berbalik ke titik ekuilibrium tidak stabil.

Segmen $\mathrm{O}_{3} \mathrm{O}_{2}$ dapat digunakan untuk aktuator pegas non-reversible seperti pada gambar 1. Secara terpisah, karakteristik torsi ini ditampilkan dalam gambar 6, dimana bagian karakteristik torsi dengan sudut putar $2 \pi$ bergeser dari titik ekuilibrium tidak stabil sebesar $q_{u}$. Jika diperlukan untuk memberikan arah gerakan, titik fiksasi harus bergeser dengan sudut kecil menuju arah gerakan, untuk menciptakan momen start yang diperlukan untuk memulai gerakan [5]. Sudut putar lengan sama dengan $2 \pi$, tapi posisi awalnya bergeser relatif terhadap posisi keseimbangan yang tidak stabil sebesar $q_{0}$ ke arah gerak. Pada keadaan ini, karakteristik momen torsi ditentukan dengan persamaan sebagai berikut:

$M=u \cdot c\left(1-\frac{u-r}{\sqrt{r^{2}+u^{2}+2 a \sigma q}}\right) \cdot \sin \left(q+q_{0}\right)$

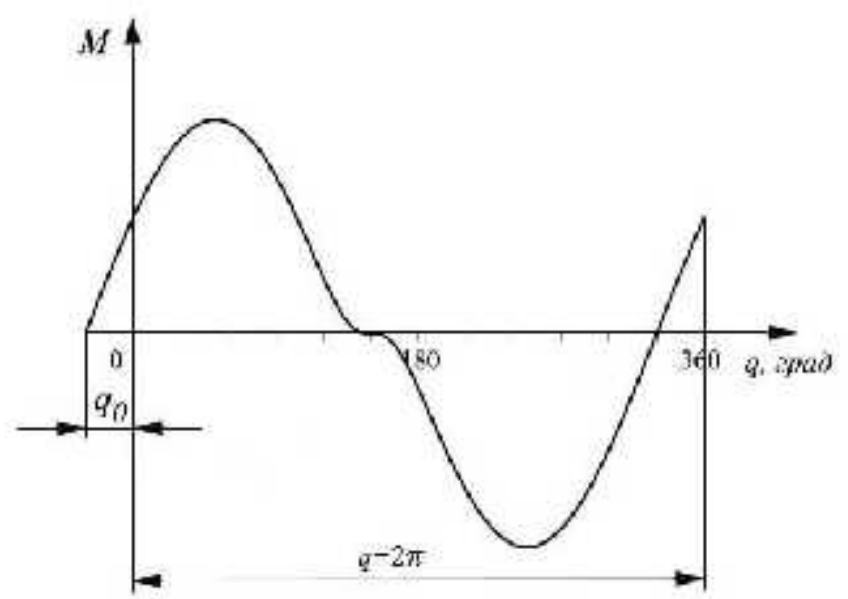

Gambar 6. Grafik karakteristik momen torsi

Pada kondisi ini, energi potensial ditentukan dengan persamaan berikut:

$$
\begin{aligned}
& V_{T}=\frac{c L_{p}{ }^{2}}{2} \\
& V_{T}=c r^{2} V_{a}
\end{aligned}
$$$$
\text { dimana }
$$

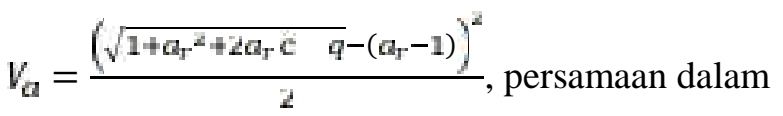

bentuk nirmatra untuk menentukan energi potensial.

Energi potensial pada kondisi ini tergantung sudut putar dari parameter desain. Waktu rotasi pada momen inersia $\mathbf{J}$ ditentukan oleh kontasnta pegas dan parameter desain $a$ dan $r$.

Untuk sudut putar $q<\pi / 2$ bisa digunakan hubungan $\sin q=q$. Sedangkan kecepatan ditentukan dengan persamaan:

$\dot{q}=\sqrt{\frac{\left(2 V_{m}-V_{T}\right)}{J}}$ 
Setelah mensubstitusi nilai maksimum dan sekarang dari enegi potensial pegas, persamaan di atas menjadi:

$\dot{q}=\sqrt{\frac{2\left(2 \mathrm{Lr} r^{2}-0,5 \mathrm{~L}\left(\sqrt{r^{2}+u^{2}+2 a \circ q}-L_{U}\right)^{2}\right)}{I}}$

atau $\dot{q}=4 r \sqrt{\frac{c}{\jmath}} \cdot \dot{q}_{a}$

dimana

$$
\dot{q}_{a}=\sqrt{4-\left(\sqrt{1+a^{\prime 2}+2 a^{r c} q}-\left(a^{\prime}-1\right)\right)^{2}}
$$

yang mana menunjukkan kecepatan sudut dalam nirmatra.

Gambar 7 menunjukkan grafik kecepatan sudut AP dalam nirmatra.

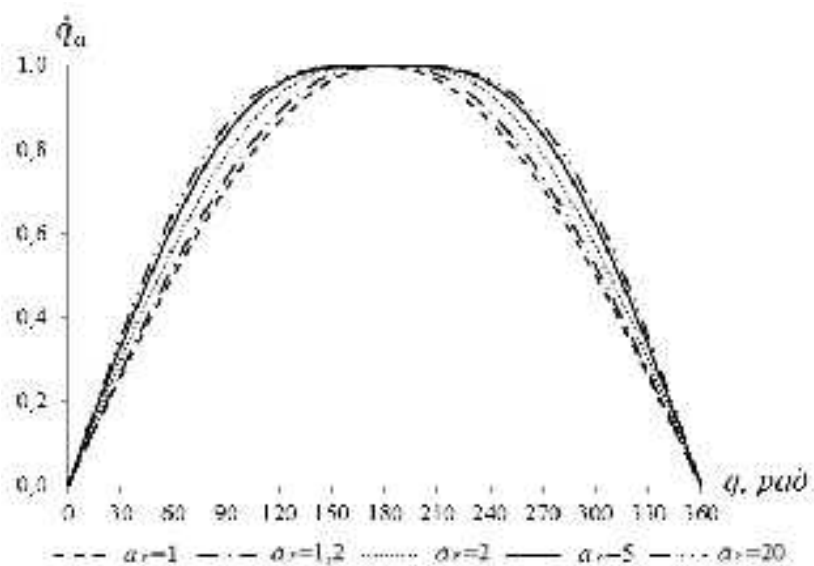

Gbr.7. Grafik karakteristik kecepatan sudut AP berbagai variasi jarak sumbu $a_{r}$

Waktu rotasi dari lengan di dua titik pada kondisi equilibrium tidak stabil diperoleh dari persamaan integral:

$t=\sqrt{\frac{j}{2}} \cdot \int_{U}^{2 \pi} \frac{d}{\sqrt{V_{\mathrm{m}}-V_{V}}}$

Persamaan di atas dapat ditulis sebagai berikut:

$t=\int_{U}^{2 \pi} \frac{d}{\dot{q}(q)}=\frac{1}{r} \sqrt{\frac{j}{c}} \cdot K_{t}$

$K_{t}=\int_{0}^{2 \pi} \frac{a}{\sqrt{q-\left(\sqrt{1+u_{\Gamma}{ }^{2}+2 u_{\Gamma} D} \nabla-\left(u_{\Gamma}-1\right)\right)^{2}}}$

Solusi persamaan (9) memungkinkan kita untuk menentukan waktu rotasi pada nilai-nilai tunggal kekakuan dan mengurangi saat inersia.

Tabel 1 menunjukkan hasil perhitungan koefisien $K_{t}$ untuk nilai yang berbeda dari parameter desain.

Transformasi persamaan (9) memungkinkan diperoleh persamaan untuk menentukan konstanta pegas:

$C=\frac{J K_{L}^{2}}{r^{2} L^{2}}$
Tabel 1 Hasil perhitungan koefisien $K_{t}$

\begin{tabular}{|c|c|c|c|c|c|c|c|c|c|c|}
$a^{*}$ & 0 & 0,1 & 0,2 & 0,3 & 0,4 & 0,5 & 0,6 & 0,7 & 0,8 & 0,9 \\
\hline 1 & 24,50 & 24,00 & 21,56 & 23,20 & 22,86 & 22,58 & 22,34 & 22,12 & 21,92 & 21,74 \\
\hline 2 & 21,58 & 21,44 & 21,30 & 21,18 & 21,06 & 20,96 & 20,86 & 20,78 & 20,70 & 20,62 \\
\hline 3 & 20,54 & 20,48 & 20,40 & 20,34 & 20,28 & 20,24 & 20,18 & 20,14 & 20,08 & 20,04 \\
\hline 4 & 20,40 & 19,96 & 10,92 & 19,88 & 19,85 & 19,82 & 19,79 & 19,75 & 19,73 & 19,70 \\
\hline 5 & 19,67 & 19,64 & 19,62 & 19,50 & 19,57 & 19,55 & 19,53 & 19,51 & 19,49 & 19,47 \\
\hline 6 & 19,45 & 19,43 & 19,41 & 19,39 & 19,18 & 10,36 & 19,35 & 19,33 & 19,32 & 19,30 \\
\hline
\end{tabular}

\section{KESIMPULAN}

1. Pada sudut rotasi $2 \pi$, kecepatan dan akselerasi terus berubah, dan perubahan ini dimulai dan diakhiri dengan nilai nol (minimum), nilai yang menguntungkan mode dinamis.

2. Dapat disimpulkan bahwa dengan mengubah parameter geometri khususnya $a_{r}$, dapat memperbesar kecepatan serta mengurangi waktu rotasi.

3. Penelitian ini dilakukan untuk melihat pengaruh parameter desain AP dan memberikan rekomendasi untuk perancang aktuator yang menggunakan pegas yang berdasar pada analisis momen torsi.

\section{DAFTAR PUSTAKA}

1. Bolotin L.M., Korendyasev A.I., Salamandra B.L., Tyves L.I. The mechanical arm, A.s. USSR No.1323378. Bulletin No.11. 1987. (rus.)

2. Babitskiy V .I., Kotlyachkov A.A., Chechurov V .A., Shipilov A.V ., Panin V.N. Resonant actuator, A.s. USSR No. 1544550. Bulletin No.7, 1990. (rus.) *

3. Bautin N.N. Dynamic theory of watches: Stabilization period in oscillatory -systems with two degrees of freedom // Nauka. 1986. 192 p. (rus.) *

4. Glushkov A.A. Research and development of high-speed rotary cyclic drives of oscillatory type: diss. ... kand. tekhn. nauk . Vladimir: VlTU Publ., 2006. 148 p. (rus.) •

5. Zhavner V .L., Zhavner M.V ., Matsko O.N. Recuperative drives for cyclic movement/ Palmarium Academic Publishing, 2014. - 90 p. (rus.) *

6. Zhavner M.V. Methods of calculation and design of actuators for robotic systems based on the spring mechanisms: avtoref. diss. ...kand. tekhn. nauk, St.Petersburg, SPbGPU Publ., 2003. 18 p. (rus.) *

7. Zaytsev V.V., Korendyasev A.I., Litovchenko A.P., Salamandra B.L., Tyves L.I., Shishkov V.S. i Sachkov L.B., Industrial robot, Patent RF, 1768381SU . Prioritet 21.01.88. 15.10.92. Byul. No.38. (rus.) * 
8. Kolchin N.I. . - M.: Mashinostroenie. , 1972.456 p. (rus.)

9. Korendyasev A.I., Salamandra B.L., Tyves L.I. The basic theory of robot technology. 2nd Vol. - $\quad \therefore$ Nauka. - 2006. - 376 p. (rus.)

10.Korendyasev A.I., Salamandra B.L., Tyves L.I. et al. Manipulative robotic $\square$ systems. - M.: Mashinostroenie. - 1989. - pp. 279-286. (rus.)

11.Landau L.D., Lifshits E.M. Theoretical physics. Vol.1. Mechanics. 4th edition, revised .- M.: Nauka. Chief editor in chief of physicmathematical literature. 1988. -216 p. (rus.)

12.Loytsyanskiy L.G., Lurye A.I. Short course of theoretical mechanics. 2nd Vol. Moscow, Nauka, 1983. -621 p. (rus.)

13.Pelupessy D.S., Zhavner M.V. Spring accumulators for stepper drives. Sovremennoe mashinostroenie. Nauka i obrazovanie: Proceedings of the 5th International Scientific and Practical Conference. St.-Petersburg: Izdatelstvo Politekhnicheskogo Universiteta. 2016. - pp.499-509. (rus.)
14.Pelupessy D.S., Zhavner M.V. Spring-loaded accumulators with the output rotary link for step movements. Proceedings of Higher Educational Institutions. Machine Building. 2016. No 10 (679). pp. 9-17. (rus.)

15.Semenozhenkov V.S. Development of theory, methods of design and creation of a recuperation devices of mechanization of forging and forming production: diss. ... d-ra. tekhn. nauk. Voronezh: VGTU Publ., 1999. 366 p. (rus.)

16.Sysoyev S.N. Improving the efficiency of auxiliary operations in automated production through the creation of high-speed cyclic mechanisms of aggregate-modular: diss. ... d-ra tekhn. nauk. Moscow: MGTU Stankin Publ., 1999. - 401 p. (rus.)

17.V.L. Zhavner and O.N. Matsko. Spring drives for reciprocal motion, Journal of Machinery Manufacture and Reliability, 2016, No.1, pp.1-5. C)Allerton Press Inc., 2016. 